\title{
Pengaruh Kualitas Pelayanan dan Lingkungan Fisik Terhadap Kepuasan Konsumen pada Cafe Unsilent Palembang
}

\author{
Novita Damayanti, Muhammad Wadud \& Roswaty \\ Universitas Indo Global Mandiri \\ Email: novitadamayanti98.nd@gmail.com
}

\begin{abstract}
This study aims to investigate the effects of service quality and physical environment on customer satisfaction at the Unsilent Cafe Palembang. Based on the Slovin formula, this study used 99 samples with an accidental technique from a population of 7,710. Data were collected through documentations and questionnaires and analysed using multiple linear regression on SPSS. The results uncover that service quality and physical environment have a positive and significant effect on customer satisfaction. The correlation coefficient $(\mathrm{R})$ of 0.749 proves that service quality and the physical environment have a strong relationship with customer satisfaction. The coefficient of determination $\left(\mathrm{R}^{2}\right)$ of 0.561 indicates that the contribution of service quality and physical environment explains consumer satisfaction by $56.1 \%$.
\end{abstract}

Keywords: service quality, physical environment, customer satisfaction.

\section{Pendahuluan}

Menurut Kotler dan Keller (2016) manajemen pemasaran adalah seni dan juga ilmu untuk menentukan pasar sasaran dan mendapatkan, menjaga, serta menumbuhkan konsumen melalui pembuatan, pengiriman dan pengkomunikasian manfaat produk bagi konsumen. Kualitas pelayanan diwujudkan melalui pemenuhan kebutuhan dan keinginan pelanggan serta ketetapan penyampaiannya dalam mengimbangi atau melampaui harapan pelanggan. Kualitas adalah keseluruhan ciri- ciri karakteristik dari suatu produk atau jasa dalam kemampuannya untuk memenuhi kebutuhan - kebutuhan yang telah ditentukan atau bersifat paten. (Lupiyoadi, 2013). Lingkungan fisik ikut mendorong kepuasan konsumen dengan adanya lingkungan fisik yang baik maka konsumen merasa nyaman serta akan merasa puas. (Mowen \& Minor, 2011). Menurut Sangadji dan Sopiah (2013) menjelaskan bahwa kepuasan atau ketidakpuasan adalah perasaan senang atau kecewa seseorang yang berasal dari perbandingan antara kesannya terhadap kinerja produk yang real atau aktual dengan kinerja produk yang diharapkan. Secara umum, kepuasan dapat diartikan sebagai adanya kesamaan antara kinerja produk dan pelayanan yang diterima dengan kinerja produk dan pelayanan yang diharapkan konsumen. Cafe Unsilent menyediakan berbagai macam menu, rasa, dan kualitas layanan yang bervariatif. Suasana ruang yang nyaman dimanfaatkan sebagai tempat berkumpul dan bersantai bersama teman dan keluarga atau sekadar melepaskan kepenatan dari rutinitas sehari-hari. Cafe Unsilent menjadi tempat berkumpul bagi anak muda dan menjadi kebiasaan berkumpul adalah dua hal yang sudah melekat. Tren ini berkembang pesat dengan hadirnya cafe. Maraknya cafe dan terutama cafe unsilent di kota palembang mengakibatkan cafe unsilent menjadi tempat interaksi sosial dan gaya hidup anak muda saat ini. Cafe unsilent tidak hanya berfungsi sebagai tempat untuk menikmati minuman dan makanan, tetapi telah menjadi sebuah tempat berkumpul, bersosialisasi, hiburan, produktivitas, dan kegiatan 
bisnis yang secara berkala dilakukan baik secara individu maupun kelompok. Berdasarkan uraian latar belakang diatas maka peneliti tertarik untuk melakukan penelitian berjudul "Pengaruh Kualitas Pelayanan dan Lingkungan Fisik Terhadap Kepuasan Konsumen Pada Cafe Unsilent Palembang". Adapun tujuan penelitian adalah untuk menganalisis: (1) Pengaruh Kualitas Pelayanan dan Lingkungan Fisik Terhadap Kepuasan Konsumen Pada Cafe Unsilent Palembang?; (2) Pengaruh Kualitas Pelayanan Terhadap Kepuasan Konsumen secara parsial Pada Cafe Unsilent Palembang?; (3) Pengaruh Lingkungan Fisik Terhadap Kepuasan Konsumen secara parsial Pada Cafe Unsilent Palembang?; (4) Pengaruh Kualitas Pelayanan dan Lingkungan Fisisk Terhadap Kepuasan Konsumen secara simultan Pada Cafe Unsilent Palembang?

\section{Tinjauan Literatur}

\subsection{Kualitas Pelayanan}

Kualitas pelayanan adalah segala bentuk aktivitas yang dilakukan oleh perusahaan guna memenuhi harapan konsumen. Pelayanan dalam hal ini diartikan sebagai jasa atau service yang disampaikan oleh pemilik jasa yang berupa kemudahan, kecepatan, hubungan, kemampuan dan keramah tamahan yang ditujukan melalui sikap dan sifat dalam memberikan pelayanan untuk kepuasan konsumen. Kualitas pelayanan (service quality) dapat diketahui dengan cara membandingkan persepsi para konsumen atas pelayanan yang nyata-nyata diterima atau peroleh dengan pelayanan yang sesungguhnya diharapkan atau inginkan terhadap atribut-atribut pelayanan suatu perusahaan (Putra, et al. 2014).

\subsection{Lingkungan Fisik}

Menurut Kurniawan dkk. (2010) Lingkungan fisik merupakan lingkungan dimana jasa diberikan untuk tempat interaksi dengan konsumen yang memfasilitasi upaya dari jasa yang diproduksi. Pelayanan jasa sifatnya tidak dapat dilihat dan disentuh, maka konsumen sering mengandalkan bukti secara fisik untuk mengevaluasi pelayanan jasa sebelum pembelian dan menilai kepuasan terhadap pelayanan jasa selama dan sesudah proses konsumsi. Lingkungan fisik terdiri dari semua elemen berwujud dan tidak berwujud yang ada di dalam dan di luar restoran. Untuk memperbaiki lingkungan fisik restoran, maka harus ada investasi secara substansial pada desain interior, dekorasi, layout, dan aksesoris lainnya, karena pengeluaran ini adalah investasi yang penting untuk menarik pelanggan.

\subsection{Kepuasan Konsumen}

Kepuasan konsumen merupakan salah satu indikator keberhasilan dari suatu usaha. Hal ini telah dipercaya secara umum karena dengan memuaskan konsumen maka organisasi dapat meningkatkan tingkat keuntungannya dan mendapatkan pangsa pasar yang lebih luas (Barsky, 1992, dalam Daryanto \& Setyobudi, 2014).

\section{Metode Penelitian}

Jenis data yang digunakan penulis dalam penelitian di Café Unsilent Palembang menurut (Sugiyono, 2017) adalah: (1) Data Kualitatif adalah data yang berbentuk kata, kalimat, gerak tubuh, ekspresi wajah, bagan, gambar, dan foto; (2) Data Kuantitatif adalah data yang berbentuk angka atau data kuantitatif yang diangkakan / scoring. Teknik pengumpulan data pada penelitian ini di lakukan dengan cara berikut: (1) Kuesioner merupakan teknik pengumpulan data yang dilakukan dengan cara memberikan 
seperangkat pertanyaan atau pernyataan tertulis kepada responden untuk dijawabnya. Kuisioner merupakan teknik pengumpulan data yang efisien bila peneliti tahu dengan pasti variabel yang akan diukur dan tahu apa yang bisa diharapkan dari responden. Kuesioner dapat berupa pertanyaan atau pertanyaan tertutup atau terbuka, dapat diberikan kepaada responden secara langsung atau dikirim melalui pos, atau internet (Sugiyono, 2017); (2) Metode dokumentasi merupakan catatan peristiwa yang sudah berlalu. Dokumen bias berbentuk tulisan, gambar, atau karya-karya monumental dari seseorang. (Sugiyono, 2017). Menurut Sugiyono (2017) Populasi adalah wilayah generalisasi yang terdiri atas objek/subjek yang mempunyai kuantitas dan karakteristik tertentu yang ditetapkan oleh peneliti untuk dipelajari dan kemudian ditarik kesimpulanya. Menurut Fauzi, Dencik dan Asiati (2019) Sampel adalah bagian dari jumlah dan karakteristik yang dimiliki oleh populasi tersebut. Bila populasi besar, dan peneliti tidak mungkin memperlajari semua yang ada pada populasi, misalnya karena keterbatasan dana, tenaga dan waktu, maka peneliti dapat menggunakan sampel yang diambil dari populasi itu. Untuk itu sampel yang diambil dari populasi harus betul-betul representatif (mewakili). Data populasi yang diperoleh cafe selama 3 bulan terakhir 7,710 konsumen, dengan menggunakan teknik sampling aksidental. Teknik analisis yang digunakan adalah uji regresi berganda.

\section{Hasil dan Pembahasan}

Penelitian ini telah dilakukan dengan menyebarkan 99 kuesioner kepada 99 responden yang terdiri dari konsumen Cafe Unsilent Palembang. Dimana sampel yang digunakan adalah berjumlah 99 kuesioner telah disebarkan dan telah kembali 99 kuesioner. Pengolahan data menggunakan SPSS Version.16 maka di dapat hasil penelitian sebagai berikut. Uji validitas digunakan untuk mengukur sah atau valid tidaknya suatu kuesioner dan uji validitas biasanya di lakukan dengan uji signifikan atau dilakukan dengan melakukan korelasi bivariate antara masing-masing skor indikator dengan total skor variabel, adapun hasil validitas kuesioner untuk variabel yang di teliti disajikan pada tabel sebagai berikut:

Tabel 1. Variabel Kualitas Pelayanan $\left(\mathrm{X}_{1}\right)$

\begin{tabular}{|l|l|l|l|l|}
\hline Item & $\mathrm{R}_{\text {Hitung }}$ & Sig & $\mathrm{R}_{\text {Tabel }}$ & Keterangan \\
\hline $\mathrm{X} 1.1$ & 0,748 & 0,000 & 0,1975 & Valid \\
\hline $\mathrm{X} 1.2$ & 0,666 & 0,000 & 0,1975 & Valid \\
\hline $\mathrm{X} 1.3$ & 0,690 & 0,000 & 0,1975 & Valid \\
\hline $\mathrm{X} 1.4$ & 0,679 & 0,000 & 0,1975 & Valid \\
\hline $\mathrm{X} 1.5$ & 0,786 & 0,000 & 0,1975 & Valid \\
\hline
\end{tabular}

Tabel 2. Variabel Lingkungan Fisik $\left(\mathrm{X}_{2}\right)$

\begin{tabular}{|l|l|l|l|l|}
\hline Item & $\mathrm{R}_{\text {Hitung }}$ & Sig & $\mathrm{R}_{\text {Tabel }}$ & Keterangan \\
\hline X2.1 & 0,739 & 0,000 & 0,1975 & Valid \\
\hline X2.2 & 0,699 & 0,000 & 0,1975 & Valid \\
\hline X2.3 & 0,734 & 0,000 & 0,1975 & Valid \\
\hline X2.4 & 0,662 & 0,000 & 0,1975 & Valid \\
\hline
\end{tabular}


Tabel 3. Variabel Kepuasan Konsumen(Y)

\begin{tabular}{|l|l|l|l|l|}
\hline Item & $\mathrm{R}_{\text {Hitung }}$ & Sig & $\mathrm{R}_{\text {Tabel }}$ & Keterangan \\
\hline Y1.1 & 0,727 & 0,000 & 0,1975 & Valid \\
\hline Y1.2 & 0,815 & 0,000 & 0,1975 & Valid \\
\hline Y1.3 & 0,784 & 0,000 & 0,1975 & Valid \\
\hline Y1.4 & 0,884 & 0,000 & 0,1975 & Valid \\
\hline
\end{tabular}

Pada ketiga tabel di atas terlihat bahwa hasil uji validitas data menunjukkan semua butir pertanyaan valid, karena $\mathrm{R}_{\text {Hitung }}$ lebih besar dari $\mathrm{R}_{\text {Tabel }}=0,1975$ dan setiap pertanyaan sudah berkorelasi signifikan $(a<0,05)$ sehingga dapat di simpulkan bahwa semua item pertanyaan dinyatakan valid .

Uji realiabilitas dimaksudkan untuk mengukur suatu kuesioner yang merupakan indikator dari variabel, reliabilitas dapat di ukur dengan menggunakan uji statistikcronbach'salpha (a), pada suatu variabel dikatakan reliabel jika memberikan nilai cronbach'salpha $>0,06$. Semakin nilai alphanya mendekati satu maka nilai realiabilitas datanya semakin terpercaya untuk masing-masing variabel. Hasil pengujian realiabilitas data dapat dilihat pada tabel berikut ini :

Tabel 4. Hasil Uji Realiabilitas

\begin{tabular}{|l|l|l|l|}
\hline Variabel & $\begin{array}{l}\text { Cronchbach'sAlp } \\
\text { ha }\end{array}$ & Ketentuan & Hasil \\
\hline $\mathrm{X}_{1}$ & 0,783 & 0,6 & Reliabel \\
\hline $\mathrm{X}_{2}$ & 0,746 & 0,6 & Reliabel \\
\hline $\mathrm{Y}$ & 0,813 & 0,6 & Reliabel \\
\hline
\end{tabular}

Hasil uji realiabilitas tersebut menunjukkan semua variabel mempunyai koefisien alpha yang cukup besar yaitu di atas 0,6 sehingga dapat dikatakan semua konsep pengukur masing-masing variabel dari kuesioner realiabilitas sehingga untuk selanjutnya item-item pada masing-masing konsep variabel tersebut layak digunakan sebagai alat ukur.

Di mana untuk mengetahui apakah populasi data berdistribusi normal atau tidak. Uji ini biasanya digunakan untuk mengukur data berskala ordinal, interval, dan rasio

Tabel 5. Hasil Uji Normalitas One-sampleKolmogorov

One-Sample Kolmogorov-Smirnov Test

\begin{tabular}{|ll|l|}
\hline & & $\begin{array}{l}\text { Unstandardized } \\
\text { Residual }\end{array}$ \\
\hline N & & 99 \\
Normal Parameters ${ }^{\mathrm{a}}$ & Mean & .0000000 \\
& Std. Deviation & 1.41418790 \\
Most Extreme Differences Absolute & .092 \\
& Positive & .071 \\
& Negative & -.092 \\
Kolmogorov-Smirnov Z & & .914 \\
Asymp. Sig. (2-tailed) & & .373 \\
\hline
\end{tabular}

a. Test distribution is Normal. 
Dari hasil uji normalitas menggunakan metode One-SampleKolmogorov-Smirnov didapat hasil signifikasi dari uji normalitas sebesar 0,373 di mana hasil tersebut lebih besar dari taraf signifikansi 0,05 sehingga dapat disimpulkan bahwa uji test normalitas pada penelitian ini adalah terdistribusi normal.

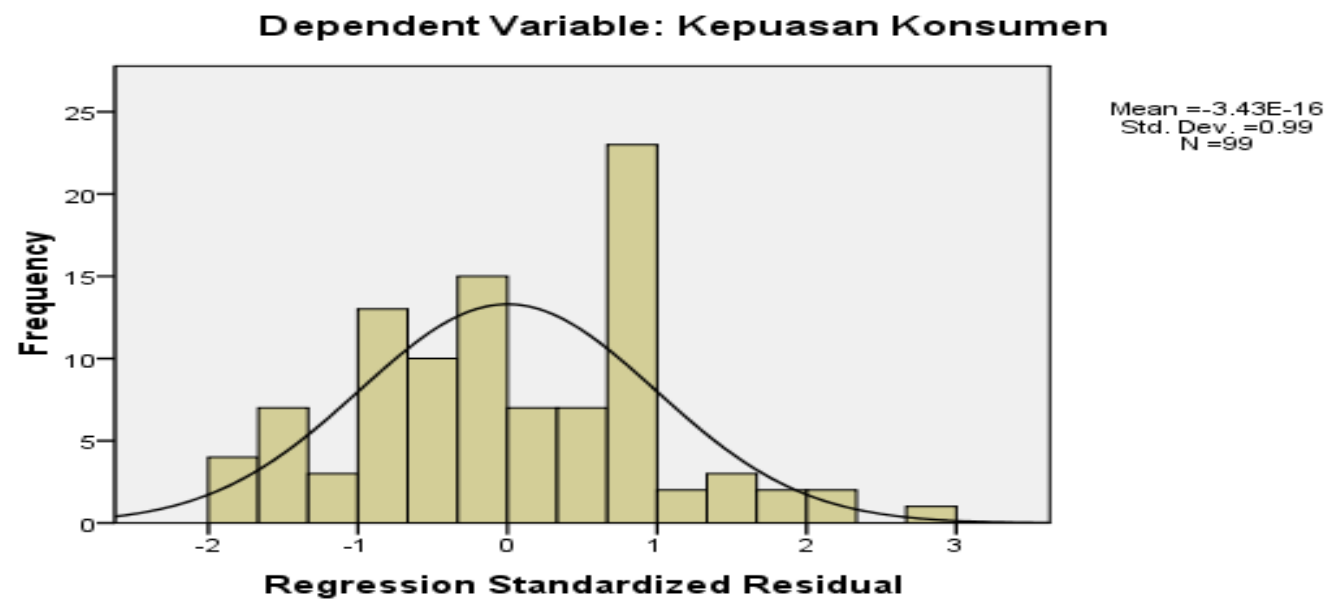

Gambar 1. Hasil Uji Normalitas - Histrogram

Grafik membentuk gunung atau lonceng. Maka dengan ini data residual terdistribusi secara normal.

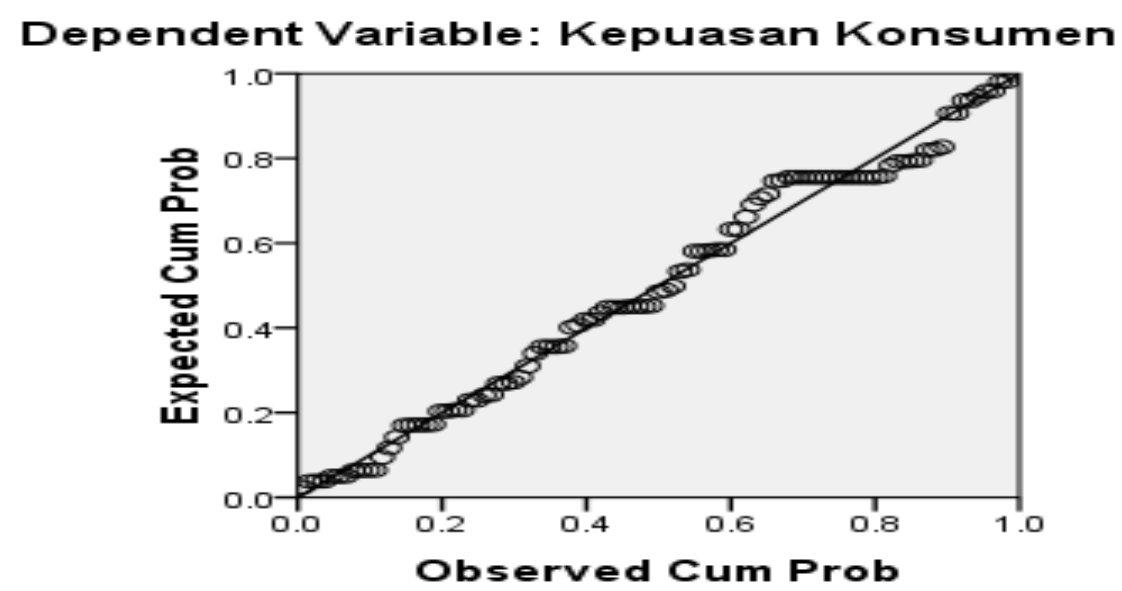

Gambar 2. Hasil Uji Normalitas - P-P Plot

Grafik normal P-P Plot bahwa titik sekitar garis dan mengikuti garis diagonal. dengan ini maka data residual terdistribusi normal.

Uji Signifikasi Parsial (Uji t) menunjukkan hasil seberapa besar atau ada tidaknya hubungan antar variabel secara parsial terhadap variabel dependen yang berguna untuk membuktikan hipotesis yang diajukan oleh peneliti, berikut disajikan output uji parsial dari variabel Kualitas Pelayanan $\left(\mathrm{X}_{1}\right)$, Lingkungan Fisik $\left(\mathrm{X}_{2}\right)$, terhadap variabel dependen Kepuasan Konsumen (Y). 
Tabel 6. Hasil Uji t Parsial Kualitas Pelayanan $\left(\mathrm{X}_{1}\right)$

\begin{tabular}{|c|c|c|c|c|c|c|}
\hline \multirow{2}{*}{\multicolumn{2}{|c|}{ Model }} & \multicolumn{2}{|c|}{$\begin{array}{l}\text { Unstandardized } \\
\text { Coefficients }\end{array}$} & \multirow{2}{*}{$\begin{array}{l}\text { Standardized } \\
\text { Coefficients } \\
\text { Beta }\end{array}$} & \multirow[b]{2}{*}{$\mathrm{t}$} & \multirow[b]{2}{*}{ Sig. } \\
\hline & & $B$ & Std. Error & & & \\
\hline 1 & (Constant) & 4.844 & 1.681 & & 2.881 & .005 \\
\hline & $\begin{array}{l}\text { Kualitas Pelayanan } \\
\left(\mathrm{X}_{1}\right)\end{array}$ & .546 & .077 & .585 & 7.096 & .000 \\
\hline
\end{tabular}

a. Dependent Variable: Kepuasan Konsumen

Dari hasil perhitungan di atas diketahui bahwa nilai Kualitas Pelayanan $\left(\mathrm{X}_{1}\right)$ t-hitung sebesar 7,096 >t-tabel 1,984 (7,096>1,984) dan sig 0,000<0,05 $(0,000<0,05)$. Sehingga $\mathrm{H}_{1}$ diterima dan dapat disimpulkan bahwa Kualitas Pelayanan $\left(\mathrm{X}_{1}\right)$ memiliki kontribusi atau berpengaruh terhadap kepuasan konsumen (Y) sebesar 70,96\%.

Tabel 7. Hasil Uji t Parsial Lingkungan Fisik $\left(\mathrm{X}_{2}\right)$

\begin{tabular}{|c|c|c|c|c|c|c|}
\hline & & \multicolumn{2}{|c|}{$\begin{array}{l}\text { Unstandardized } \\
\text { Coefficients }\end{array}$} & \multirow{2}{*}{\begin{tabular}{|l} 
Standardized \\
Coefficients \\
Beta \\
\end{tabular}} & \multirow[b]{2}{*}{$\mathrm{T}$} & \multirow[b]{2}{*}{ Sig. } \\
\hline \multicolumn{2}{|c|}{ Model } & B & Std. Error & & & \\
\hline \multirow[t]{2}{*}{1} & (Constant) & 3.187 & 1.277 & & 2.496 & .014 \\
\hline & $\begin{array}{l}\text { Lingkungan } \\
\text { Fisik }\left(\mathrm{X}_{2}\right)\end{array}$ & .780 & .073 & .734 & 10.659 & .000 \\
\hline
\end{tabular}

a. Dependent Variable: Kepuasan

Konsumen

Dari hasil perhitungan di atas diketahui bahwa nilai Lingkungan Fisik $\left(\mathrm{X}_{2}\right)$ t-hitung sebesar 10,659 > t-tabel 1,984 $(10,659>1,984)$ sehingga Lingkungan Fisik $\left(\mathrm{X}_{2}\right)$ sangat berpengaruh / berkontribusi terhadap kepuasan konsumen (Y), sedangkan sig 0,000< 0,05 dimana Lingkungan Fisik $\left(\mathrm{X}_{2}\right)$ memiliki pengaruh signifikan terhadap Kepuasan Konsumen (Y) sebesar 10,65\%.

Uji Signifikan Simultan (Uji F) untuk mengetahui signifikan atau tidak pengaruh variabel bebas secara bersama-sama terhadap variabel terikat.

Tabel 8. Hasil Uji Signifikasi Simultan (uji F)

ANOVA ${ }^{\mathbf{b}}$
\begin{tabular}{|ll|lr|l|l|l|l|}
\hline \multicolumn{2}{|l|}{ Model } & $\begin{array}{l}\text { Sum } \\
\text { Squares }\end{array}$ & of & Df & Mean Square & F & Sig. \\
\hline 1 & Regression & 250.512 & 2 & 125.256 & 61.352 & $.000^{\mathrm{a}}$ \\
& Residual & 195.993 & 96 & 2.042 & & \\
& Total & 446.505 & 98 & & & \\
\hline
\end{tabular}

a. Predictors: (Constant), Lingkungan Fisik, Kualitas Pelayanan

b. Dependent Variable: Kepuasan Konsumen 
Pada tabel 8 dapat dilihat bahwa nilai Fhitung 61,352 > Ftabel 3,09 dan nilai sig 0,000< 0,05 . Hal ini menunjukkan bahwa variabel bebas yang terdiri dari variabel independen Kualitas Pelayanan dan Lingkungan Fisik berpengaruh secara simultan (bersama-sama) positif dan signifikan terhadap variabel dependen yaitu Kepuasan Konsumen sebesar $61,352 \%$.

Analisis Regresi Linier Berganda digunakan untuk mengetahui besarnya variabel independen (bebas) Kualitas Pelayanan $\left(\mathrm{X}_{1}\right)$ dan Lingkungan Fisik $\left(\mathrm{X}_{2}\right)$ terhadap variabel dependen (terikat) Kepuasan Konsumen (Y).

Tabel 9. Tabel Regresi Linier Berganda

\section{Coefficients $^{\mathrm{a}}$}

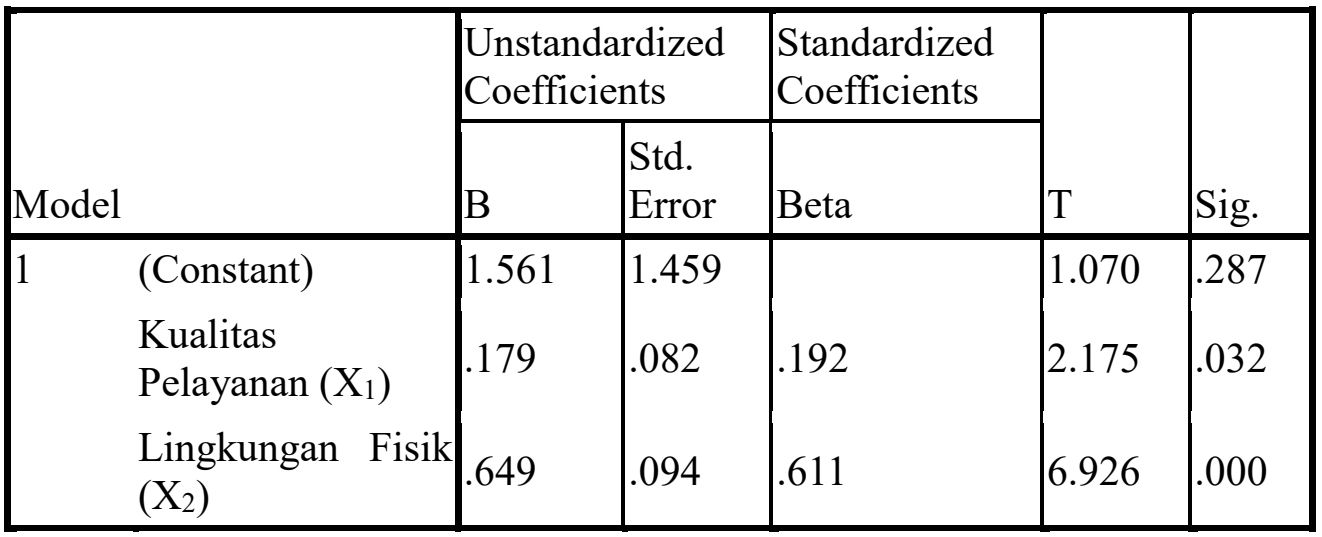

a. Dependent Variable: Kepuasan Konsumen

Berdasarkan tabel 4.17 hasil SPSS versi 16 di atas didapatkan persamaan regresi linier berganda sebagai berikut :

$\mathrm{Y}=1,561+0,179 \mathrm{X}_{1}+0,649 \mathrm{X}_{2}+\mathrm{e}$

Nilai konstanta (a) adalah sebesar 1,561 hal ini menyatakan bahwa jika nilai variabel kualitas pelayanan $\left(\mathrm{X}_{1}\right)$ dan lingkungan fisik $\left(\mathrm{X}_{2}\right)$ atau sama dengan nol, maka nilai kepuasan konsumen adalah sebesar 1,561 dan menunjukkan hasil positif. Kualitas Pelayanan $\left(\mathrm{X}_{1}\right)$ koefisien regresinya sebesar 0,179 menunjukkan bahwa variabel kualitas pelayanan $\left(\mathrm{X}_{1}\right)$ berpengaruh positif terhadap kepuasan konsumen $(\mathrm{Y})$ artinya apabila kualitas pelayanan meningkat 1\% maka kepuasan konsumen juga akan meningkat 0,179 .

Lingkungan fisik $\left(\mathrm{X}_{2}\right)$ koefisien regresinya sebesar 0,649 menunjukkan bahwa variabel lingkungan fisik $\left(\mathrm{X}_{2}\right)$ berpengaruh positif terhadap kepuasan konsumen $(\mathrm{Y})$. Artinya apabila lingkungan fisik meningkat $1 \%$ maka kepuasan konsumen juga akan meningkat 2,389. Dari hasil estimasi regresi terlihat bahwa kualitas pelayanan mempunyai pengaruh yang lebih tinggi atau signifikan dibandingkan lingkungan fisik terhadap kepuasan konsumen pada Cafe Unsilent Palembang, yang didasarkan pada nilai koefisien regresi 0,179 (UnstandardizedCoeffcients) dan nilai Beta 0,192 (StandardizedCoefficients) dengan nilai signifikan sebesar 0,032 .

Koefisien korelasi adalah nilai yang menunjukkan kuat atau tidaknya hubungan linier antara dua variabel. Koefisien korelasi biasa dilambangkan dengan huruf $\mathrm{R}$ di mana nilai $\mathrm{R}$ dapat bervariasi dari -1 sampai +1 . Nilai $\mathrm{R}$ yang mendekati -1 atau +1 menunjukkan hubungan yang kuat antara dua variabel. Nilai $\mathrm{R}$ yang mendekati 0 mengindikasikan 
lemahnya hubungan antara dua variabel tersebut. Dengan hasil pengelolaan SPSS diperoleh hasil sebagai berikut

Tabel 10. Hasil Uji Koefisien Determinasi

\begin{tabular}{|l|l|l|l|l|}
\hline Model & $\mathrm{R}$ & R Square & $\begin{array}{l}\text { Adjusted } \\
\text { Square }\end{array}$ & $\begin{array}{l}\text { Std. Error of } \\
\text { the Estimate }\end{array}$ \\
\hline 1 & $.749^{\mathrm{a}}$ & .561 & .552 & 1.429 \\
\hline
\end{tabular}

a. Predictors: (Constant), Lingkungan Fisik, Kualitas Pelayanan

b. Dependent Variable: Kepuasan Pelanggan

Dari tabel 10 menunjukkan bahwa nilaiR 0,749 berarti hubungan (relation) antara Kualitas Pelayanan dan Lingkungan Fsisik terhadap Kepuasan Konsumen memiliki hubungan yang sedang sebesar $74 \%$.

R Square sebesar 0,561 atau 56,1\% menunjukkan bahwa variabel kepuasan konsumen yang dapat dijelaskan oleh kualitas pelayanan dan lingkungan fisik adalah $0,561 \%$ sedangkan 0,676 atau 67,6\% dijelaskan oleh faktor-faktor lain yang tidak dijelaskan oleh faktor lain. Adjusted R Square sebesar 0,552 atau 55,2 \%.

\section{Kesimpulan}

Berdasarkan analisis dan pembahasan yang telah diuraikan maka dapat ditarik kesimpulan sebagai berikut: (1) Hasil penelitian dengan menggunakan Uji-t variabel Kualitas Pelayanan $\left(\mathrm{X}_{1}\right)$, menghasilkan thitung $>\mathrm{t}_{\text {tabel }}(7,096>1,984)$ dan taraf $\operatorname{sig}(0,000<$ $0,05)$, jadi dapat disimpulkan secara parsial variabel Kualitas Pelayanan $\left(\mathrm{X}_{1}\right)$ berpengaruh positif dan signifikan Terhadap Kepuasan Konsumen Pada Cafe Unsilent Palembang; (2) Hasil penelitian dengan menggunakan Uji-t variabel Lingkungan Fisik $\left(\mathrm{X}_{2}\right)$, menghasilkan $t_{\text {hitung }}>t_{\text {tabel }}(10,659>1,984)$ dan taraf sig $(0,000<0,05)$, jadi dapat disimpulkan secara parsial variabel Lingkungan Fisik $\left(\mathrm{X}_{2}\right)$ berpengaruh positif dan signifikan Terhadap Kepuasan Konsumen Pada Cafe Unsilent Palembang; (3) Hasil penelitian dengan menggunakan Uji f variabel Kualitas Pelayanan $\left(\mathrm{X}_{1}\right)$ dan Lingkungan Fisik $\left(\mathrm{X}_{2}\right)$ menghasilkan $\mathrm{f}_{\text {hitung }}>\mathrm{f}_{\text {tabel }}(61,352>3,09)$ dan taraf $\operatorname{sig}(0,000<0,05)$. Jadi dapat disimpukan secara simultan Kualitas Pelayanan $\left(\mathrm{X}_{1}\right)$ dan Lingkungan Fisik $\left(\mathrm{X}_{2}\right)$ berpengaruh positif dan signifikan terhadap Kepuasan Konsumen (Y); (4) Hasil penelitian dengan menggunakan Uji Koefesien Korelasi (R) diperoleh nilai 0,749. Jadi dapat disimpulkan hubungan antara variabel Kualitas Pelayanan $\left(\mathrm{X}_{1}\right)$ dan Lingkungan Fisik $\left(\mathrm{X}_{2}\right)$ mempunyai hubungan erat/kuat terhadap Kepuasan Konsumen (Y) 74,9\%; (5) Koefesien Determinasi $\left(\mathrm{R}^{2}\right)$ menunjukkan nilai 0,561 dapat disimpulkan besarnya kontribusi variabel Kualitas Pelayanan ( $\mathrm{X}_{1}$ ) dan Lingkungan Fisik (X2) bisa menjelaskan variabel Kepuasan Konsumen (Y) sebesar 56,1\% dan sedangkan sisanya 43,9\% bisa dijelaskan / dipengaruhi oleh variabel lain yang tidak dijelaskan dalam penelitian ini.

Bagi Cafe Unsilent Palembang harus memberikan pelayanan yang lebih baik pada konsumen agar konsumen merasa puas dengan pelayanan yang diberikan, dan harus memperhatikan lingkungan disekitar cafe sehingga membuat konsumen betah dan nyaman. Pada variabel kualitas pelayanan diharapkan Cafe Unsilent Palembang masih perlu dilakukan perbaikan dalam dimensi responsiveness (ketanggapan), dalam hal lama 
waktu menunggu menyajikan menu dapat dilakukan dengn lebih cepat, sehingga konsumen tidak menunggu terlalu lama. selain itu menyediakan wadah dimana para konsumen dapat mengutarakan keluhan dan kritik tentang apa saja yang kurang dari Cafe Unsilent Palembang dan sebaiknya Cafe Unsilent Palembang menyediakan promosi yang menggabungkan pembelian makanan dan minuman. Pada variabel lingkungan fisik diharapkan lebih memperhatikan dan menambah lagi pencahayaan dibagian-bagian yang masih kurang pencahayaan agar konsumen cafe unsilent merasa nyaman, seperti bagian pencahayaan spot berfoto agar menarik minat konsumen untuk berfoto. Pada variabel kepuasan konsumen diiharapkan Cafe Unsilent Palembang harus slalu memperhatikan tingkat kepuasan konsumen dengan cara selalu mengevaluasi untuk lebih memperhatikan pelayanan, produk, maupun harga, seperti cepat tanggap dalam memberikan menu makan. Selain itu produk yang disajikan harus sesuai dengan harga yang telah ditentukan.

\section{Referensi}

Mowen, J.C., \& Minor, M. (2019). Perilaku Konsumen. Jakarta: Erlangga.

Kurniawan, DAA., Karenilla, \& Jakom, R. (2010). Analisis Pengaruh Lingkungan Fisik Terhadap Niat Berperilaku Melalui Emosi Konsumen Di Domicile Kitchen \& Lounge Surabaya. Universitas Kristen Petra Surabaya.

Daryanto, \& Setyobudi, I. (2014). Konsumen dan Pelayanan Prima. Yogyakarta: Gava Media

Fauzi, F., Dencik, A. B., \& Asiati, D. I. (2019). Metodologi Penelitian Untuk Manajemen dan AKuntansi. Jakarta: Salemba Empat.

Kotler, P., \&. Amstrong, G. (2016). Principles of marketing 16th Edition. England: Pearson

Lupiyoadi, R. (2013). Manajemen Pemasaran Jasa, Edisi Ketiga. Jakarta: Salemba Empat.

Putra, Arfian Bimantara., et. al. (2015). Pengaruh Bauran Pemasaran Jasa Terhadap Keputusan Pembelian (Survei pada Pelanggan yang Menggunakan Jasa Penggiriman di Kantor Pos Besar Kota Malang). Jurnal Administrasi Bisnis (JAB). Vol. 1 No. 1 Januari 2015. Hal 1-8.

Sangadji, EM., \& Sophia. (2013). Perilaku Konsumen - Pendekatan Praktis disertai Himpunan Jurnal Penelitian. Yogyakarta: ANDI.

Sugiyono. (2017). Metode Penelitian Kuantitatif, Kualitatif dan R\&D (Cetakan Ke). Bandung: Alfabeta.

\section{Copyrights}

Copyright for this article is retained by the author(s), with first publication rights granted to the journal.

This is an open-access article distributed under the terms and conditions of the Creative Commons Attribution license (http://creativecommons.org/licenses/by/4.0/) 